Outros Tempos, vol. 17, n. 30, 2020, p. 134 - 155. ISSN: 1808-8031

DOI: http://dx.doi.org/10.18817/ot.v17i30.805

\title{
O COTIDIANO DO HOSPITAL DE CARIDADE DE SÃO LUÍS E A CRISE DA ASSISTÊNCIA NA SEGUNDA METADE DO SÉCULO XIX ${ }^{1,2}$
}

\author{
EVERYDAY LIFE OF A CHARITY HOSPITAL IN SÃO LUÍS AND THE SOCIAL CARE \\ CRISIS AT THE SECOND HALF OF THE 19TH CENTURY
}

\section{TODOS LOS DÍAS EN EL HOSPITAL DE CARIDAD DE SÃO LUÍS Y UNA CRISIS DE ASISTENCIA EN LA SEGUNDA MITAD DEL SIGLO XIX}

\author{
AGOSTINHO JÚNIOR HOLANDA COE \\ Professor Adjunto III da Universidade Federal do Piauí \\ Campus Ministro Petrônio Portela - CCHL - Dpto de História \\ Piauí - Teresina - Brasil \\ agostinhocoe@ufpi.edu.br
}

\begin{abstract}
Resumo: A Irmandade da Misericórdia foi fundada em São Luís por volta de 1623. Em 1642, a Irmandade já havia construído uma igreja e um cemitério e, em 1653, já haviam projetos para a construção de um hospital. No século XIX administrava um cemitério, o Hospital de Caridade e dos Lázaros, além da Roda e Casa dos Expostos. Diante de tal crescimento do poderio e importância da assistência praticada pelos congregados na Irmandade da Misericórdia, analisaremos como o tratamento dispensado aos doentes no Hospital de Caridade foi se tornando cada vez mais um "grande fardo" para a Misericórdia, já que, na segunda metade do século XIX, as reclamações eram recorrentes acerca da dificuldade do cuidado para com os enfermos em virtude do acirramento de crises financeiras. Como o século XIX, em São Luís, foi marcado pelas diversas epidemias que assolavam os aglomerados urbanos, também estudaremos a assistência no contexto dos surtos epidêmicos e as transformações que tais epidemias proporcionaram ao Hospital de Caridade.
\end{abstract}

Palavras-chave: Hospital. Caridade. Assistência. Crise.

Abstract: The Irmandade da Misericórdia was founded in São Luís, around 1623. In 1642 the Irmandade had already built a church and a cemetery, and by 1653 there were already projects for the construction of a hospital. In the 19th century, they were managing a cemetery, the Hospital de Caridade and Hospital dos Lázaros, in addition to the Roda and Casa dos Expostos. In view of such an increase in the power and importance of the assistance practiced by the congregants of the Irmandade da Misericórdia, we will analyze how the treatment given to patients at the Hospital de Caridade was increasingly becoming a "great burden" for the Misericórdia, as, during the second half of the 19th century, there were recurring complaints regarding the difficulty of caring for the sick due to the intensification of financial crises. As the 19th century in São Luís was marked by the various epidemics that plagued urban agglomerations, we will also study assistance in the context of epidemic outbreaks and the transformations that such epidemics have brought to the Hospital de Caridade.

Keywords: Hospital - Charity - Assistance - Crisis.

Resumen: La Irmandade da Misericórdia fue fundada en São Luís alrededor de 1623. En 1642, la Irmandade ya había construido una iglesia y un cementerio, y en 1653 ya habían proyectos para la construcción de un hospital. En el siglo XIX, dirigía un cementerio, el Hospital de Caridade y de

\footnotetext{
${ }^{1}$ Artigo submetido à avaliação em janeiro de 2020 e aprovado para publicação em junho de 2020.

2 Este texto é parte da minha tese de doutorado, A assistência em crise: a Santa Casa da Misericórdia do Maranhão na segunda metade do século XIX (1850-1890), concluída em 2013 no Programa de Pós-Graduação em História das Ciências e da Saúde da Casa de Oswaldo Cruz - COC/Fiocruz.
} 
Outros Tempos, vol. 17, n. 30, 2020, p. 134 - 155. ISSN: 1808-8031

Lázaros, además de la Roda y la Casa dos Expostos. En vista de tal aumento en el poder y la importancia de la asistencia practicada por los congregantes en la Irmandade da Misericórdia, analizaremos cómo el tratamiento dado a los pacientes en el Hospital de Caridade se estaba convirtiendo cada vez más en una "gran carga" para la Misericórdia, puesto que, desde la segunda mitad del siglo XIX, las quejas son recurrentes sobre la dificultad de cuidar a los enfermos debido a la intensificación de las crisis financieras. Como el siglo XIX, en São Luís, estuvo marcado por las diversas epidemias que plagaron las aglomeraciones urbanas, también estudiaremos la asistencia en el contexto de brotes epidémicos y las transformaciones que tales epidemias han traído al Hospital de Caridade.

Palabras clave: Hospital. Caridad. Asistencia. Crisis.

A primeira notícia sobre a criação de um hospital em São Luís pela Irmandade da Misericórdia ${ }^{3}$ é trazida pelo padre Antônio Vieira:

\begin{abstract}
A maior parte deste ano de 1653 passou-a o pe. Antônio Vieira na cidade de São Luís [...] Procurou também fazer erigir um hospital, e a esse intento despertou o zelo da Irmandade da Misericórdia, que arrecadou não poucas esmolas; mas como a obra por então não fosse adiante, conseguiu sempre que se dispusesse uma casa particular para receber os enfermos de todo desamparados, e em favor desse hospital provisório privou-se ele mesmo de muitas comodidades indispensáveis, dando-lhe até a própria cama, e dormindo daí por diante em uma simples esteira de tábua ${ }^{4}$.
\end{abstract}

Entretanto, apesar de projetos anteriores, o Hospital de Caridade da Santa Casa só foi construído em 1805, nas cercanias do templo administrado pela Irmandade - Igreja de São Pantaleão, conforme as afirmações encontradas nas Atas das Sessões da Santa Casa da Misericórdia do Maranhão:

Foi mandado edificar em 16 de Maio de 1805, pelo provedor da Santa Casa o general D. Francisco de Mello Manoel da Camara, para nelle serem recolhidos os

\footnotetext{
${ }^{3}$ As Misericórdias surgiram em Lisboa, no ano de 1498, com objetivo de centralizar iniciativas individuais numa instituição que pudesse decidir a quem deveria ser praticada a caridade. A ideia era criar critérios claros de definição do "verdadeiro pobre", selecionando dentro de um contingente amplo de desamparados socialmente quais deveriam ser os eleitos para receber a devida assistência. Ao contrário das outras irmandades religiosas, que destinavam seu auxílio principalmente aos associados ou irmãos, as Misericórdias assumiram funções bastante amplas, tais como: construção e administração de hospitais, concessão de dotes a mulheres órfãs para a realização do casamento, fornecimento de abrigo a crianças abandonadas ou órfãs, construção e administração de cemitérios, administração de imóveis e capitais de crédito, comparecimento às festas, enterros e peditórios organizados pela irmandade, o que distingue os trabalhos desempenhados pelas Misericórdias em relação às outras associações religiosas. Soma-se a isso, a prática corriqueira de visitar presos para fornecer auxílio espiritual, comida, aceleração de processos judiciais, além da visita aos doentes em seus domicílios. Muitas associações religiosas buscaram equiparar-se ao protagonismo das Misericórdias, muitas vezes, fazendo frente aos serviços praticados pela entidade. Ver: SÁ, Isabel dos Guimarães. Quando o rico se faz pobre: misericórdias, caridade e poder no império português, 1500-1800. Lisboa: Comissão Nacional para as comemorações dos descobrimentos portugueses, 1997. p. 34; FRANCO, Renato. Pobreza e caridade leiga: as Santas Casas de Misericórdia na América Portuguesa. 2011. Tese (Doutorado em História Social) - Universidade de São Paulo, São Paulo, 2011. p. 6.

${ }^{4}$ MARQUES, César Augusto. Dicionário histórico-geográfico da Província do Maranhão. São Luís: AML, 2008. p. 362.
} 
Outros Tempos, vol. 17, n. 30, 2020, p. 134 - 155. ISSN: 1808-8031

enfermos pobres desta então Capitania, os quaes, como ficou dito em outra parte, eram tratados no limitado consistorio da Igreja de São Pantaleão .

Antes da construção do referido estabelecimento, os enfermos, em São Luís, eram tratados no Hospital Militar. Todavia, mesmo com o novo hospital, a Santa Casa continuou a utilizar o espaço destinado aos militares para realizar os curativos dos pobres até por volta de 1833, pois o edifício criado inicialmente para receber os enfermos desvalidos em São Luís era, segundo fontes da época, pequeno e de estrutura deficiente. Por escritura de 29 de outubro de 1833, D. Rosa Helena Barbosa de Albuquerque, viúva e herdeira do CirurgiãoMor Manuel de Matos Sagunto, fez doação de um terreno para a construção de um novo hospital de caridade à Santa Casa. Esse novo hospital teria sido preparado para receber pelo menos 100 enfermos anuais. Segundo o jornal "Publicador Maranhense”, de 1834, "no espaço de nove meses já haviam entrado mais de 80 doentes de um e outro sexo, dos quais só três faleceram, saindo os mais curados".

A historiadora Maria Renilda Nery Barreto, ao estudar o Hospital São Cristóvão em Salvador, informa-nos que o mesmo também funcionou até 1833, em acanhadas residências situadas nas imediações da sede da Misericórdia, e que na segunda década do século XIX, o hospital teve grandes dificuldades para atender à demanda de doentes ${ }^{6}$. Ainda segundo a historiadora, o Hospital São Cristóvão, aos moldes do Hospital de Caridade de São Luís, também tinha nas doações das famílias mais abastadas da Bahia uma das suas principais fontes de recursos, recebendo contribuições de comerciantes e de estrangeiros que morriam nas enfermarias. Além das doações particulares, também contava com contribuições do Estado por meio da prestação de serviços médico-cirúrgicos que eram destinados aos presos, aos soldados e aos marinheiros, também complementava suas rendas com os lucros advindos de propriedades rurais pertencentes à Santa Casa e à administração de loterias, bem como a partir das diárias pagas por pacientes particulares ${ }^{7}$.

O Hospital de Caridade de São Luís, além de subsídios governamentais, contava com diversos legados que eram deixados em favor da Misericórdia. Quando da sua edificação, o provedor José Gonçalves da Silva forneceu todas as alfaias e arranjos necessários para o hospital, deixando ainda em seu testamento a quantia de 20:000 réis e, mais, na instituição de

\footnotetext{
${ }^{5}$ Fala com que o Exm. Sr. Conselheiro João Capistrano Bandeira de Mello abriu a $1^{a}$ sessão da $26^{a}$ legislatura da Assembleia Legislativa Provincial do Maranhão, em 13 de março de 1886. Maranhão, Typ. do Paiz, [n.d.].

${ }^{6}$ BARRETO, Maria Renilda Nery. A medicina luso-brasileira: instituições, médicos e populações enfermas em Salvador e Lisboa (1808-1851). 2005. Tese (Doutorado em História das Ciências) - Fundação Oswaldo Cruz, Rio de Janeiro, 2005. p.181.

${ }^{7}$ Ibid., p. 187.
} 
Outros Tempos, vol. 17, n. 30, 2020, p. 134 - 155. ISSN: 1808-8031

seu morgado, o valor de 25:000 réis, que eram pagos anualmente no dia do seu aniversário. Devido à tamanha "gentileza", recebeu o privilégio de ter o seu retrato a óleo estampado na entrada do hospital, trazendo ainda os seguintes dizeres: "Sempre te seremos gratos pelos largos donativos que de tua mão receberam em alimentos e esmolas os pobres, os enfermos e infelizes" $"$.

O referido Hospital era ainda encarregado de socorrer os pobres, escravos, com os quais não queriam se misturar os grandes proprietários de terras e comerciantes portugueses. Os lusitanos que aqui residiam e que não queriam ou já estavam em estado avançado de suas doenças para receber auxílios médicos em suas residências, por exemplo, tinham como opção o Hospital Português de São João de Deus, construído pela Real Sociedade Humanitária em $1^{\circ}$ de Dezembro, em 1867, e que teve, desde a sua fundação, a função de receber principalmente os portugueses que precisavam ser tratados, mas não optavam por despender cuidados médicos no Hospital de Caridade da Misericórdia.

Mesmo recebendo boa parte dos pobres e desvalidos em São Luís, a partir de 1815, o Hospital de Caridade da Misericórdia também tratou de construir espaços para admitir pensionistas, cobrando-lhes uma diária de 1280 réis. Essa era uma forma de aumentar os rendimentos do Hospital, pois eram recorrentes as reclamações acerca dos parcos recursos governamentais e do caráter oneroso do cuidado com os doentes, pois a cada dia o público que adentrava nos espaços médicos era composto em sua maioria de escravos e desvalidos, o que fazia com que a garantia do recebimento de algum provento se tornasse cada vez mais difícil. A mistura dos pensionistas com indivíduos considerados de estirpe inferior era uma das principais causas da recusa pelo tratamento no Hospital de Caridade, por isso, em 1828, providenciou-se uma reforma e uma ampliação de suas instalações, para assim receber indivíduos que pudessem e quisessem pagar pelos serviços médicos.

Todavia, uma contradição ia se acirrando ao longo da necessidade de levantar maiores recursos para o Hospital, pois uma das obrigações instituídas em seu compromisso, e legitimada pelas administrações locais com auxílios periódicos, era sempre reservar a maior parte do seu espaço para o tratamento e a alimentação gratuita dos doentes indigentes na capital. Entrementes, o que se percebe na prática é que a instituição vai se tornando cada vez mais dependente das contribuições particulares, notadamente, na segunda metade do século XIX, o que leva a uma diminuição gradativa dos espaços reservados aos mais destituídos materialmente.

\footnotetext{
${ }^{8}$ MARQUES, op. cit., p. 345.
} 
Outros Tempos, vol. 17, n. 30, 2020, p. 134 - 155. ISSN: 1808-8031

Comparando o funcionamento do Hospital de Caridade de São Luís com o hospital administrado pela Santa Casa do Rio de Janeiro, podemos perceber que o funcionamento do nosocômio, no contexto carioca, também vai ficando cada vez mais dependente dos recursos daqueles que podiam pagar pelos serviços ali praticados. A historiadora Tânia Salgado Pimenta, lembra que uma característica da maioria dos enfermos tratados nos hospitais de caridade era a pobreza. Ao menos, a direção do hospital do Rio de Janeiro não media esforços para que tal premissa fosse levada em consideração, pois a própria instituição o definia como "[...] um asilo dos doentes pobres" 9 .

Ainda segundo Tânia Pimenta, no Hospital de Caridade do Rio de Janeiro também se cobravam daqueles que tinham melhores condições financeiras, já os que não tinham condições de pagar tinham que ser enviados para o Hospital portando, no mínimo, um pedido de internamento assinado por uma autoridade. Como forma de aumentar os recursos que entravam no Hospital de Caridade carioca, em 1835, a Mesa aumentou o valor do curativo e deliberou que os escravos e os indivíduos livres que pudessem se curar às suas custas deveriam pagar mil réis diários ${ }^{10}$. O estudo da historiadora Renilda Barreto sobre o Hospital de São Cristóvão na Bahia revelou que o nosocômio baiano, na primeira metade do século XIX, não foi o lugar por excelência de tratamento do negro escravo ou forro, e do branco desvalido. Essa população se fez presente nos atendimentos ali realizados, mas a maioria dos enfermos era composta de brancos e estrangeiros, com ocupação definida. Assim como o Hospital de Caridade ludovicense e carioca, o Hospital de São Cristóvão também foi ficando cada vez mais dependente no século XIX de contribuições daqueles que podiam pagar pelos atendimentos, gerando polêmicas sobre o pouco espaço reservado para o tratamento de pobres e escravos ${ }^{11}$.

Entretanto, o tratamento aos escravos e aos desvalidos nunca foi interrompido por completo no Hospital de Caridade de São Luís, pois, em 1815, a Câmara resolveu contratar um médico para o curativo dos pobres. Para tal atividade, foi admitido o médico Joaquim José Coelho Rodrigues de Melo, com o vencimento de 400 réis, pagos anualmente. Posteriormente, foi contratado o cirurgião Antônio José Pinto, que já prestava serviço gratuito no hospital desde a sua abertura e que teve a sua admissão apenas confirmada junto com os acertos em relação à remuneração anual. Tais medidas buscavam melhorar o atendimento nos

\footnotetext{
${ }^{9}$ PIMENTA, Tânia Salgado. Transformações no exercício das artes de curar no Rio de Janeiro durante a primeira metade do Oitocentos. 2003. Tese (Doutorado em História Social) - Universidade Estadual de Campinas, Campinas, 2003. p. 147.

${ }^{10}$ Ibid., p. 187.

${ }^{11}$ BARRETO, op. cit., 2005, p. 232.
} 
Outros Tempos, vol. 17, n. 30, 2020, p. 134 - 155. ISSN: 1808-8031

espaços hospitalares, haja vista o aumento gradativo da quantidade de pacientes tratados ali. Em 1837, o Hospital fazia cerca de 300 atendimentos anuais e os valores a serem pagos pelos pensionistas eram: "Oficial do Exército, da Armada, de Polícia ou de pessoa semelhante, 2\$000; Praças de pré dos mesmos corpos, 1\$800; Alienados em célula, \$800; Ditos em enfermaria, 1\$600; Escravos, 1\$800; Morféticos, $\$ 500 " 12$.

Desde os primórdios da Santa Casa da Misericórdia no século XIX, haviam reclamações sobre a ineficiência das mesas que administravam o Hospital de Caridade. O referido estabelecimento havia adquirido grande importância dentro do orçamento da Misericórdia, pois se tratava do espaço que gerava as maiores despesas em comparação com o cemitério, a Casa dos Expostos e o Hospital dos Lázaros (outras das instituições administradas pela Santa Casa da Misericórdia). Gradativamente, as suas instalações antigas e o pouco espaço físico tornaram-se insuficientes para abarcar a quantidade de doentes na capital, notadamente em momentos de surtos epidêmicos. O referido Hospital, em comparação com as outras instituições administradas pela Santa Casa, era o local em que era atendido o maior número de pessoas diariamente, o que aumentava a responsabilidade dos que ali trabalhavam. Não foram poucos os relatos acerca da falta de profissionais capazes de atender a grande quantidade de pacientes que procuravam atendimento, bem como a escassez dos recursos que eram disponibilizados pelas administrações provinciais. Quase sempre era preciso retirar haveres dos enterramentos, local de maior superávit para a Misericórdia e, assim, cobrir rombos deixados pelos atendimentos nos hospitais.

Nos anos de 1856/1857, momento de grande comprometimento do orçamento da Santa Casa, a cidade foi acometida por um grande surto de disenteria, que teve início em setembro de 1855, acometendo principalmente as crianças, os velhos e os caquéticos. Não foi somente a capital que se viu atormentada com a epidemia, o estado sanitário de todo o interior foi alterado. A epidemia foi identificada pelas autoridades provinciais como sendo fruto da entrada da Cólera na capital, ceifando grande quantidade de vidas. Além disso, em 1856 a febre amarela, que já havia reinado em 1851, reapareceu na capital ajudando no aumento da despesa do Hospital de Caridade. Em 1856 foram 1127 mortos, cerca de 300 foram vítimas dos surtos de cólera, em relação à febre amarela foram cerca de 50 casos, com uma média de 18 mortos pela doença. Em 1857, o problema maior foi com os doentes que vieram do interior para serem tratados no Hospital, o que comprometeu boa parte do orçamento da Santa Casa

\footnotetext{
12 ARQUIVO PÚBLICO DO ESTADO DO MARANHÃO (APEM). Caixa 1 - Secretário da Mesa da Santa Casa da Misericórdia / Presidente da Província do Maranhão (1830-1847).
} 
Outros Tempos, vol. 17, n. 30, 2020, p. 134 - 155. ISSN: 1808-8031

da Misericórdia. A grande despesa com os doentes perdurou até 1858 em virtude da carência de farinha e carne verde, principais gêneros para a alimentação, o que dificultou a recuperação da população mais pobre.

Em 1865/66, o problema foi a Varíola que apresentou um número crescente de vítimas e invadiu diversos pontos do interior. O movimento das enfermarias do Hospital de Caridade foi bastante intenso nesses anos, pois uma das medidas para conter o surto epidêmico foi oferecer abrigo aos militares, aos educandos acometidos pela doença e aos presos de justiça. Entretanto, a epidemia foi menos intensa do que a de 1854-55, pois de outubro de 1854 a dezembro de 1855 houveram 683 pessoas acometidas pela Varíola, já no período de outubro de 1864 a maio de 1866, foram 505 acometidos pela doença, o que demonstra um decréscimo de 178 doentes.

Tais dados demonstram que em períodos de "normalidade" o Hospital de Caridade do Maranhão já comprometia boa parte do orçamento da Santa Casa da Misericórdia, em momentos de surtos epidêmicos a despesa ganhava tamanha proporção que a instituição demorava vários anos para reorganizar minimamente suas contas, isso quando não era surpreendida por novos surtos em curtos espaços de tempo.

Em comparação a outros hospitais administrados pela Santa Casa, tais como o do Rio de Janeiro e da Bahia, a média de mortalidade no Hospital de Caridade de São Luís estava dentro dos padrões aceitáveis para a época. Todavia, eram os picos de óbitos nos momentos de epidemia que acirravam a incapacidade do referido estabelecimento em lidar com os momentos de maior adversidade. Quando do aparecimento de surtos epidêmicos, quase sempre outros espaços eram alugados para auxiliar na contenção de doenças, aguçando as dificuldades estruturais do Hospital e retomando debates acerca das melhorias necessárias. A falta de estrutura ficava mais visível em momentos críticos, e, era bastante comum as fontes analisadas apontarem para a ineficiência dos serviços ali prestados em relação ao tratamento dispensado aos doentes, servindo o hospital muito mais como lugar de contaminação do que como local de restabelecimento da saúde. Eis uma média da entrada e saída de pacientes no Hospital de Caridade em 1839 e a despesa anual com o estabelecimento: “[...] em termo medio, 270 doentes, dos quaes morrem 51, vindo assim a mortalidade á ser de 23 por cento [...] Este Hospital faz annualmente a despeza de 13:400\$ reis, pouco mais ou menos"13.

\footnotetext{
${ }^{13}$ APEM. Discurso que recitou o Exm. Sr. Manoel Felisardo de Sousa e Mello, presidente desta província, na ocasião da abertura da Assembleia Legislativa Provincial no dia 3 de maio do corrente ano. Maranhão, Typ. de I.J. Ferreira, 1839.
} 
Outros Tempos, vol. 17, n. 30, 2020, p. 134 - 155. ISSN: 1808-8031

As reclamações sobre a diminuta quantia despendida para o cuidado dos doentes eram extremamente frequentes. Em 1839, a quantia de Mil e Quinhentos réis mal dava para pagar o salário dos funcionários que trabalhavam em favor dos convalescentes. Além das despesas com os pacientes, havia grande reclamação sobre o caráter oneroso do trabalho realizado com os lázaros. Tendo como exemplo outras realidades brasileiras, tais como Rio de Janeiro e Bahia, em que os encargos com os leprosos eram divididos com as administrações provinciais, a reclamação das mesas em relação ao peso gerado pelo acúmulo de funções com o Hospital dos Lázaros tornava-se cada vez mais recorrente em virtude da pouca contribuição governamental nos primórdios do século XIX. Recurso empregado em favor dos Lázaros significava menores possibilidades de melhoria para o Hospital de Caridade, sendo as despesas com as enfermidades de escravos, pensionistas e pobres, suficientes para comprometer parte considerável do ordenado acumulado pela Misericórdia anualmente. Além disso, nada no Compromisso obrigava a Misericórdia a tratar dos leprosos, fato sempre lembrado pelos presidentes de província quando as contas da instituição eram sobrecarregadas pela quantia despendida com o Hospital dos Lázaros. Em 1840, Luiz Alves de Lima afirma:

\begin{abstract}
Existem, sob a inspecção da Mesa da Santa Casa da Misericordia, o Hospital dos Lazaros, e o Geral, em que se recolhem todos os doentes, excepto os affectados de moléstia contagiosa. Ao primeiro suppre o Thesouro Publico Provincial com a quantia de 1:500\$reis, extremamente diminuta, pois que a despesa indispensável para não perecerem à mingoa os infelises, que ahi se achão, eleva-se á mais de 2:600\$ reis, recahindo o excesso correspondente sobre os reditos da Misericordia, quando o compromisso, que actualmente a rege, nenhuma obrigação lhe impõem de sustentar os enfermos atacados de Elefantiasis, sendo elles em outros lugares mantidos á custa do Governo, ou de patrimônio privado ${ }^{14}$.
\end{abstract}

Apesar do prédio que abrigava os doentes do Hospital de Caridade ser fruto de incessantes reclamações acerca de suas condições físicas, esse era o melhor espaço, se comparado tanto aos lugares que abrigavam expostos e lázaros como ao cemitério que recebia os mortos da capital. A média de 350 enfermos que adentravam ao Hospital de Caridade, por ano, gerava uma despesa média de 10:600 réis, valor considerado alto pelas Mesas Administrativas da Misericórdia, principalmente, em períodos de maior crise financeira ou surtos epidêmicos.

\footnotetext{
${ }^{14}$ APEM. Fala que recitou o Exm. Presidente e comandante das armas da província do Maranhão, o coronel Luiz Alves de Lima, n'abertura da Assembleia Legislativa Provincial no dia 3 de maio de 1840. Maranhão, Typ. de I.J. Ferreira, 1840.
} 
Outros Tempos, vol. 17, n. 30, 2020, p. 134 - 155. ISSN: 1808-8031

Em 1844, segundo o presidente da província, João Jozé de Moura Magalhães, para dirimir qualquer foco de epidemias, era preciso destinar o espaço do Hospital de Caridade para a população mais pobre, fornecer remédios gratuitamente e aumentar a quantidade de médicos e o ordenado dos mesmos, além de aumentar a capacidade de cura dos que procuravam o estabelecimento. Pagar médicos para visitar os indivíduos doentes em seus domicílios também era uma das sugestões encontradas nas discussões existentes nos Relatórios dos Presidentes de Província, até mesmo a proposta de multas aos que não quisessem se tratar era bem-vinda, assim como ensinar aos "lavradores" a melhor forma de cuidar da mão de obra escrava para que fosse possível maior controle das doenças e epidemias que mais acometiam a população local.

\begin{abstract}
Para empedir os progressos espantosos da syphilis, seria de muita utilidade franquear os hospitaes a pobresa, fornecer remedios gratuitamente, e assalariar medicos que curassem nas casas aquelles, que por peijo senão quisessem curar nos hospitaes, multar os doentes que senão quisessem curar, e ensinar aos nossos lavradores que tenhão o maior cuidado na saúde e curativo dos escravos ${ }^{15}$.
\end{abstract}

A sugestão de "franquear os hospitaes a pobresa" pode demonstrar que o referido nosocômio não tinha como prioridade o atendimento de pobres e desvalidos. Constatação parecida foi encontrada pelas historiadoras Tânia Salgado Pimenta (2003) e Maria Renilda Nery Barreto (2005), nos estudos acerca dos hospitais de Caridade do Rio de Janeiro e da Bahia, respectivamente. Os espaços destinados aos pobres nos hospitais foram ficando cada vez mais escassos, ficando a Santa Casa cada vez mais dependente dos pensionistas, que pagavam pelo seu tratamento.

Questões sobre as condições gerais do Hospital eram trazidas em relatórios que buscavam reafirmar o papel do Hospital de Caridade na cura dos doentes, a baixa taxa de mortalidade e outros elementos necessários à construção de uma imagem positiva, para a população, dos profissionais que ali administravam seus medicamentos, para que os mesmos pudessem construir maior respaldo frente às outras artes e ofícios de curar no contexto oitocentista ludovicense.

O complexo d'estas peças constitue um perfeito relatorio do estado d'este Estabelecimento. O Hospital de caridade em seguido a sua marcha regular, e de 215 enfermos, que ali tem sido recolhidos desde julho do anno passado até fevereiro d'este anno, 166 forão curados, morrerão apenas 19 , e existião $30^{16}$.

\footnotetext{
${ }^{15}$ APEM. Relatório que dirigiu o Exmo. presidente da província do Maranhão, João Jozé de Moura Magalhaes, á Assembleia Legislativa Provincial em 20 de junho de 1844. Maranhão, Typ. Maranhense, 1844.

16 Ibid.
} 
Outros Tempos, vol. 17, n. 30, 2020, p. 134 - 155. ISSN: 1808-8031

Em virtude de uma crise econômica que abalou não só as contas da Misericórdia, mas a economia maranhense na segunda metade do século XIX, houve ainda uma carestia progressiva dos gêneros alimentícios considerados de primeira necessidade. $\mathrm{O}$ fornecimento de alimentos aos enfermos ficou bastante comprometido, contribuindo para o aumento das reclamações:

\begin{abstract}
Baste para prehencher o deficit, que provem em grande parte da carestia progressiva dos gêneros alimentícios e do augmento dos ordenados do medico e cirurgião, que, sendo até aqui de $200 \$ 000$ rs. cada um, vão orçados no duplo, em razão de não haver facultativos que por menos de queirão prestar a servir esses empregos no hospital, sendo todavia de esperar que o espírito de caridade, que em todos os tempos fez a gloria de uma classe tão distincta não arrefeça por tal forma, que fiquem em abandono os míseros enfermos ${ }^{17}$.
\end{abstract}

Segundo nos informa o presidente da província, João Jozé de Moura Magalhães, a dificuldade para encontrar médicos que quisessem prestar serviços no Hospital de Caridade foi ficando cada vez mais evidente no século XIX. A solução de aumentar o salário dos profissionais de medicina, se resolvia o problema por uma parte, mas por outra, abria outro imbróglio, pois a instituição não se encontrava em condições de manter pagamentos que estivessem além das suas receitas.

Em relação à falta de leitos, uma das saídas era a realização de tratamento na residência dos doentes, tal prática vai se tornando cada vez mais corriqueira, inclusive para evitar o contágio no espaço exíguo do Hospital de Caridade. Entretanto, tais procedimentos também geravam polêmica acerca da justificativa utilizada por "especuladores", que se aproveitavam de tal possibilidade para a realização de terapêuticas consideradas equivocadas e em espaços sem condições higiênicas mínimas, contribuindo muito mais para a multiplicação de focos de infecção.

O inspector da saude publica representa contra os abusos praticados pelos especuladores que recebem bexiguentos em casas sem capacidade e condições hygienicas, prestando-lhes tratamento irregular e multiplicando ao mesmo tempo os fócos de infecção.

Aconselha elle não só a creação de um edifício sempre prompto a recolher os affectados da varíola, com proporções para receber pensionistas, como tambem medidas enérgicas para cohibir o abuso dos especuladores, obrigando os proprietários, quando não puderem medicar em suas casas seus escravos, a recolhelos àquelle estabelecimento ${ }^{18}$.

\footnotetext{
${ }^{17}$ APEM. Relatório que dirigiu o Exmo. presidente da província do Maranhão, João Jozé de Moura Magalhaes, á assembleia Legislativa Provincial em 20 de junho de 1844. Maranhão, Typ. Maranhense, 1844.

${ }^{18}$ Ibid.
} 
Outros Tempos, vol. 17, n. 30, 2020, p. 134 - 155. ISSN: 1808-8031

A discussão acerca do exercício ilegal da medicina aflorava com maior intensidade, sobretudo, nos momentos de crises epidêmicas. Com médicos em quantidade reduzida para atender à população convalescente e com uma legitimidade de suas práticas ainda em processo de construção, o exercício ilegal da profissão médica quase sempre entrava em pauta para justificar o grau de indiferença da população frente às principais medidas profiláticas de contenção de doenças e epidemias, como nos mostra o presidente João Jozé de Moura Magalhães: “As praças e ruas desta cidade demonstrão quão elevado é o grao de indifferença votado a todos esses objectos e a medida do interesse que ligamos a tal assumpto é fornecida pelo governo tolerando e sanccionando o illegal exercicio da profissão medica"19.

O presidente da província, João Jozé de Moura Magalhães, ressalta ainda, em 1844, o seu esforço e a sua dedicação para com as causas da "humanidade sofredora" e demonstra preocupação com notícias que tinham como único objetivo denegrir a imagem e a importância construída pelo Hospital de Caridade em São Luís. Em momentos de crise era preciso bom senso para que os "ares doentios" pudessem ser debelados:

O espirito publico, então, pertuba-se, como é natural: as noticias exageradas apparecem de todas as partes, sem aquelle bom senso indispensável, em taes casos, sem a calma precisa, para não difficultar a actividade e esmorecer a dedicação das pessoas, que de bom grado se prestam para coadjuvar o governo, sempre solicito em tranquilisar os espíritos, circumscrever e debellar o mal ${ }^{20}$.

Mesmo com os problemas apontados, sempre que possível era retomado o discurso de que o Hospital de Caridade era o lugar em que o enfermo desvalido encontrava abrigo para as suas agruras cotidianas, demonstrando o papel que o referido estabelecimento desempenhava no cuidado aos mais pobres em São Luís. A criação de uma botica própria em 1853 foi motivo de comemoração, pois a compra dos remédios realizada fora do estabelecimento causava grandes transtornos com a manipulação equivocada de drogas e o atraso na entrega dos medicamentos, gerando grande desconforto para os que estavam em tratamento.

Assim que, póde-se affirma-lo hoje com toda a segurança, a caridade e beneficência são uma realidade nos hospitaes da Santa Casa: o enfermo desvalido, que os procura, encontra ahi os socorros, que lhe proporciona tão pio estabelecimento.

Contribue tambem para este resultado a utilíssima creação, que se fez ultimamente dentro do hospital, de uma botica dirigida por um hábil pharmaceutico, a qual, com

\footnotetext{
${ }^{19}$ Ibid.

${ }^{20}$ Ibid.
} 
Outros Tempos, vol. 17, n. 30, 2020, p. 134 - 155. ISSN: 1808-8031

rapidez e á qualquer hora, fornece os medicamentos precisos, manipulados com as melhores drogas, que se encontrão no mercado. A despesa com a botica não tem excedido as sommas, que se gastavão anteriormente com a compra, por via de arrematação, dos remédios já manipulados, nos quaes não se podia ter a mesma confiança $^{21}$.

Ao longo do século XIX, a botica do Hospital abriu e fechou suas portas várias vezes, quase sempre, os motivos apontados era a dificuldade financeira para mantê-la funcionando, além da escassez de profissionais interessados em administrar o recinto. Segundo o Presidente da Província Eduardo Olimpio Machado, em 1853, a existência da botica no Hospital era uma das principais explicações para o período de calmaria, pois os gastos anteriores com a compra eram extremamente dispendiosos para o estabelecimento.

O problema maior era sempre para os pacientes que dependiam do tratamento gratuito dispensado pelo Hospital, pois as vagas eram ínfimas e, em momentos de crises financeiras, a prioridade era dada aos que podiam pagar e, assim, contribuir para amortizar as dívidas da instituição. Praças da armada, gente da marinha mercante, colonos da Província, presos de justiça, escravos (diária paga por seus senhores) e outras pessoas que ali quisessem se tratar precisavam desembolsar determinadas quantias pelos serviços prestados no Hospital da Santa Casa.

O Hospital de caridade mantem 30 doentes á custa da Santa Casa, e admitte, mediante uma justa retribuição, praças da armada, gente da marinha mercante, colonos da Provincia, presos de justiça, escravos e outras pessoas, que ahi se querem tractar. O anno passado tractarão-se no hospital 546 enfermos, dos quaes sahirão curados 417 , fallecerão 86 , e ficarão em tractamento 43.

A necessidade de alguns quartos, onde se recolhão os alienados, que vagão pelas ruas, ou são recolhidos á prisão, tem sido sentida e exposta por todos os Provedores, e a sua satisfação não pode por mais tempo ser adiada ${ }^{22}$.

Quando as contas apertavam, a ameaça era inclusive de fechamento do hospital. No ano de 1858, bem como em outros anteriores, o provedor da Santa Casa, João Lustosa da Cunha Paranaguá, informou que a Mesa Administrativa viu-se obrigada a cortar algumas despesas, reduzindo ordenados de médicos e enfermeiros, suprimindo outras demandas financeiras, tais como: a eliminação de verbas destinadas para esmolas aos pobres, a não celebração da festa de São José e da procissão dos Ossos, duas obrigações constituintes do Compromisso da Irmandade da Misericórdia em São Luís, com o intuito de diminuir em parte

\footnotetext{
${ }^{21}$ APEM. Relatório do presidente da província do Maranhão, o doutor Eduardo Olímpio Machado, na abertura da Assembleia Legislativa Provincial no dia $1 . o$ de novembro de 1853, acompanhado do orçamento da receita e despesa para o ano de 1854. Maranhão, Typ. Constitucional de I.J. Ferreira, 1853.

${ }^{22}$ APEM. Relatório que á assembleia Legislativa Provincial do Maranhão apresentou na sessão ordinária de 1857 o presidente da província, Dr. Benvenuto Augusto de Magalhães Taques. Maranhão, Typ. da Temperança, 1857.
} 
Outros Tempos, vol. 17, n. 30, 2020, p. 134 - 155. ISSN: 1808-8031

o déficit no orçamento da Santa Casa. Mesmo com tais cortes a instituição esteve prestes a fechar as portas do hospital aos enfermos indigentes, que ali iam mendigar remédios às suas agruras cotidianas $^{23}$.

$\mathrm{O}$ apelo era pela caridade, pois os ordenados recebidos pelos profissionais que trabalhavam no Hospital eram cada vez menores e a dificuldade para encontrar alguém que se dispusesse a realizar os serviços médicos no Hospital de Caridade ia se acentuando. A invocação para sensibilizar médicos e cirurgiões a realizarem seus trabalhos a preços módicos tornou-se reivindicação difícil de ser atendida, em virtude dos pesados trabalhos a serem realizados no que tange ao trato com os doentes, fazendo com que poucos médicos estivessem interessados em disponibilizar seus trabalhos de forma gratuita ou a preços abaixo do mercado.

Quando havia relativa alta na quantidade de falecidos nos hospitais, a justificativa era a não observância dos próprios pacientes dos procedimentos necessários para se recobrar a saúde, sendo que a maioria das pessoas entrava no hospital já em fase terminal de suas doenças, o que dificultava sobremaneira o trabalho realizado no nosocômio. Seria esse um argumento para apenas justificar procedimentos inadequados nos hospitais e acobertar possíveis falhas na estrutura das instituições administradas pela Santa Casa da Misericórdia? Além disso, tal justificativa utilizada pelos profissionais que tomavam conta do Hospital de Caridade pode significar a predominância de outras práticas de cura perante a população local, o que levava vários indivíduos a buscarem os hospitais somente quando outros tratamentos não eram eficazes na cura de suas enfermidades. Tal comentário reforça, ainda, a ideia do Hospital como um espaço muito mais para se "morrer" ou para um descanso momentâneo, do que para a cura das doenças. Algumas explicações momentâneas eram utilizadas, tais como o tratamento dispensado aos colonos em 1859:

O numero dos fallecidos, que orça pela $5^{\mathrm{a}}$ parte, parecerá talvez excessivo, não tendo
havido epidemia durante o anno; mas se se attender que muitos enfermos de
caridade são pelos parentes levados ao hospital no ultimo período da enfermidade,
para que a misericórdia lhes faça enterro, a ponto de entrarem n'um dia e fallecerem
no outro ou d'ahi a dias, este reparo se tornará sem duvida menos sensível. Accresce
que n'uma cidade, onde não há hospícios para receber a velhice indigente e os
alienados, a necessidade publica, superior aos regulamentos, obriga muitas vezes a
admittir no hospital os decrepitos abandonados e os alienados, o que contribue para

\footnotetext{
${ }^{23}$ APEM. Relatório do Presidente da província do Maranhão, o doutor João Lustosa da Cunha Paranaguá, na abertura da Assembleia Legislativa Provincial no dia 3 de maio de 1859. Maranhão, na Typ. de J.M.C. de Frias, 1859.
} 
Outros Tempos, vol. 17, n. 30, 2020, p. 134 - 155. ISSN: 1808-8031

augmentar a mortalidade, bem como os estragos que causão as febres nos colonos não acclimatados, recebidos no mesmo estabelecimento ${ }^{24}$.

Além dos decrépitos que adentravam no Hospital de Caridade e ajudavam na constituição de maiores estatísticas de falecidos, um dos maiores medos dos que passavam pelo estabelecimento era contrair alguma doença contagiosa que pudesse acirrar o estado de convalescença. Como forma de dirimir contágios, buscava-se o cuidado para que não adentrassem aos hospitais indivíduos com doenças infectocontagiosas. Geralmente, o tratamento das doenças "perigosas" era feito em residências escolhidas estrategicamente e por indivíduos que colocavam à disposição suas casas para o tratamento dos enfermos, tais casos aconteciam principalmente nos momentos em que as epidemias mais avassaladoras resolviam aparecer. A atitude de fiscalizar a entrada de doentes com moléstias infectocontagiosas servia para resguardar da contaminação o espaço dos hospitais, pois tais surtos poderiam levar a óbito pessoas que estivessem internadas no Hospital de Caridade para cuidar de enfermidades mais simples de serem tratadas. Todavia, em alguns momentos essa regra não era cumprida na sua inteireza, conforme nos informa o presidente-provedor Antônio Manoel de Campos Mello em 1862:

Em Janeiro entrou no hospital da Santa Casa da Misericordia um individuo affectado de varíola, vindo do sul no vapor Paraná, o qual foi logo posto em isolamento em casa de uma mulher, que prestou-se a tratal-o, e foram tomadas as possíveis precauções, para evitar-se a sua propagação. Outro caso ainda se deo em uma mulher, que foi tratada em outra casa com feliz sucesso. Alem destes não consta que se desse mais algum ${ }^{25}$.

Os espaços destinados aos doentes pobres foram ficando cada vez mais ínfimos na segunda metade do século XIX. Em 1867, por exemplo, eram somente 32 leitos para os enfermos desvalidos, ficando o restante dos espaços reservados para os que podiam pagar pelo atendimento. Em períodos epidêmicos, tal escassez de leitos causava verdadeiro pânico à população, porque num estabelecimento abarrotado de doentes o risco de contágio poderia ser muito maior, o que justificava mais ainda a ideia do Hospital como lugar muito mais para "se morrer", do que para se recobrar a saúde. A recorrente reclamação das autoridades sobre o caráter de decrepitude dos pacientes que adentravam aos espaços do Hospital entrava em

\footnotetext{
${ }^{24}$ APEM. Relatório do Presidente da província do Maranhão, o doutor João Lustosa da Cunha Paranaguá, na abertura da Assembleia Legislativa Provincial no dia 3 de maio de 1859. Maranhão, na Typ. de J.M.C. de Frias, 1859.

25 APEM. Relatório que á assembleia Legislativa Provincial do Maranhão apresentou o presidente da província, conselheiro Antônio Manoel de Campos Mello, por ocasião da instalação da mesma assembleia no dia 27 de outubro de 1862. San' Luiz, Typ. de B. de Mattos, 1862.
} 
Outros Tempos, vol. 17, n. 30, 2020, p. 134 - 155. ISSN: 1808-8031

choque com as incapacidades estruturais do local, pois segundo o presidente-provedor Manoel Jansen Ferreira:

Alem dos doentes pensionistas, como sejam as praças da marinha, de policia, presos de justiça e alienados, são alli tratados os enfermos desvalidos, para os quaes dispõe apenas o hospital de 32 leitos, numero que não está em relação com a cifra da população ${ }^{26}$.

Algumas reclamações recaiam sobre o mordomo dos hospitais e sua responsabilidade em relação à entrada e saída de pacientes. As enfermarias precisavam estar abertas a qualquer hora do dia ou da noite para todo e qualquer indivíduo, mas alguns perigos momentâneos se sobressaiam, conforme apontado pelo presidente-provedor Antonio Olimpio Gomes de Castro em 1871:

Recommendei em data de 14 de junho ao mordomo dos hospitaes da Santa Casa da Misericordia, a quem foram confiados o fornecimento e a fiscalisação d'esta enfermaria, que a tivesse sempre aberta e prompta para receber a qualquer hora do dia ou da noite os doentes, que se apresentassem a reclamar os socorros da caridade publica.

Vindo ao meu conhecimento que em uma casa da rua de Santa Rita, existia na maior miseria uma familia de seis pessoas accomettidas de bexigas, determinei ao mesmo mordomo em 16 de junho que encarregasse o medico desse estabelecimento e um enfermeiro do tractamento da referida família, mandando ministrar-lhe para esse fim os medicamentos e dietas necessárias. Foi Ella convenientemente tractada, e restabeleceu-se, como me fez constar o referido mordomo o cidadão Manoel Antonio Rodrigues Pinheiro, que é digno de todo elogio pelo zelo, actividade e dedicação com que sempre se há prestado no desempenho das ordens d'esta presidência, tendentes a socorrer os doentes desvalidos ${ }^{27}$.

A prática da caridade era sempre lembrada como elemento essencial para amenizar as dificuldades financeiras e estruturais relativas ao tratamento de doentes no Hospital de Caridade. Em 1876, eram 48 doentes pobres internados no Hospital, com isso, o presidente-provedor, Frederico D’Almeida e Albuquerque, enfatizou que somente o espírito caritativo era capaz de dar conta de tamanha responsabilidade, frente às condições precárias que iam se avolumando. "Actualmente existem em tratamento 48 pessoas, que estariam

\footnotetext{
${ }^{26}$ APEM. Relatório que o exm. Snr. primeiro vice-presidente da província, dr. Manoel Jansen Ferreira, apresentou á Assembleia Legislativa Provincial no dia 3 de maio de 1867. Maranhão, Typ. do Frias, 1867.

${ }^{27}$ APEM. Relatório lido pelo excelentíssimo senhor presidente, dr. A.O. Gomes de Castro, por ocasião da instalação da Assembleia Legislativa desta província no dia 3 de maio de 1871. San' Luiz do Maranhão, Typ. B. de Mattos, 1871.
} 
Outros Tempos, vol. 17, n. 30, 2020, p. 134 - 155. ISSN: 1808-8031

reduzidas á mizeria se as não socorresse o espirito de caridade, que, como sabeis, é a syntese da verdadeira religião de Christo" ${ }^{28}$.

Apesar das dificuldades, as baixas estatísticas de mortos em períodos de normalidade eram utilizadas para construir a imagem do Hospital como espaço de cura e não de morte. Segundo o presidente-provedor, Francisco Maria Correia de Sá Benevides, 17\% de falecidos, no ano de 1877, era um número condizente com o objetivo dos profissionais que ali trabalhavam, pois ele considerava que números de falecidos abaixo dos $20 \%$ eram os mais ideais para as estatísticas médicas naquele momento. "É de 17 por cento a mortalidade calculada sobre o movimento geral do referido hospital e enfermarias annexas, durante o dito anno. Esta cifra basta para provar o empenho e solicitude que a Santa Casa dispensa áquelles que recorrem á sua proteção" 29 .

Em 1880, ressaltando o bom trabalho realizado no cemitério administrado pela Misericórdia, o presidente-provedor Luiz de Oliveira Lins de Vasconcelos comenta sobre a má gerência dos recursos destinados aos hospitais. Além de despesas excessivas, aponta a falta de asseio e o abandono de suas instalações, demonstrando certa surpresa em relação às reclamações acerca dos parcos recursos públicos para a manutenção dos hospitais:

\begin{abstract}
Mereceu a minha especial attenção o serviço feito por esta instituição, não só pela natureza delle, como pela posição que em relação á irmandade occupa a provincia, e não devo occultar que o único serviço, que revelava cuidado e zelo da parte da pessoa delle encarregado, era o Cemiterio.

Os hospitaes de caridade e lazaros nada apresentavam que justificasse a quantia que absorviam com o seu custeio. Eram excessivas as despezas com estes estabelecimentos: ao mesmo tempo que revelavam elles pela falta de asseio, alem de outros factos, o mais censuravel abandono ${ }^{30}$.
\end{abstract}

O cuidado maior com o cemitério se justificava por ser essa a instituição que mais gerava receita para a Santa Casa? Certo é que os hospitais (Caridade e dos Lázaros) eram o principal ponto de discordância no que tange à necessidade ou não de mais recursos públicos. Como o Hospital de Caridade era o espaço que demandava a maior quantidade de dividendos a serem disponibilizados, havia sempre a alegação de que a oferta de vagas no

\footnotetext{
${ }^{28}$ APEM. Relatório com que o presidente da província, o exm. sr. senador Frederico d'Almeida e Albuquerque, abriu a assembleia Legislativa Provincial no dia 20 de junho de 1876. Maranhão, Typ. do Frias, 1876.

${ }^{29}$ APEM. Relatório que s. exc. o sr. dr. Francisco Maria Correia de Sá e Benevides, no dia 18 de outubro de 1877, apresentou á assembleia Legislativa Provincial, por ocasião da instalação de sua sessão ordinária. Maranhão, Typ. do Paiz, 1877.

30 APEM. Relatório apresentado por s. exc. o snr. presidente da província, dr. Luiz de Oliveira Lins de Vasconcellos, á assembleia Legislativa Provincial, por ocasião de sua instalação no dia 13 de fevereiro do corrente ano. Maranhão, Typ. do Paiz, 1880.
} 
Outros Tempos, vol. 17, n. 30, 2020, p. 134 - 155. ISSN: 1808-8031

estabelecimento era impossível de abarcar a procura pela cura no Hospital, mesmo em momentos de normalidade, ou seja, períodos em que São Luís não era acometido por algum surto epidêmico.

Em meio a crises financeiras, algumas mudanças vão sendo implementadas. Gradativamente, os espaços dentro do Hospital foram separados para não misturar indivíduos de categorias sociais mais prestigiadas com enfermos indigentes e escravos. Tais medidas visavam uma melhor organização do cotidiano do Hospital e construir uma imagem positiva acerca do ambiente hospitalar, facilitando a incorporação da ideia de que o Hospital de Caridade era um lugar em que as hierarquias sociais também eram respeitadas. “Art. 65. Os officiaes e praças que baixarem ao hospital são considerados pensionistas e como taes occuparão compartimentos especiaes e jamais estarão promiscuamente com os enfermos indigentes" ${ }^{\prime 3}$.

Todavia, a polêmica acerca da mistura dos indigentes e dos escravos com pacientes internados no Hospital, que buscavam fazer valer a quantia investida para assim terem determinadas regalias, foi recorrente no século XIX, pois tal "promiscuidade" poderia supostamente causar maior possibilidade de contágio para os doentes pensionistas. Havia, ainda, a dificuldade de separação dos doentes contagiosos daqueles padecentes de enfermidades mais fáceis de curar. Os leprosos, por exemplo, sofreram com a falta de espaços específicos suficientes para a realização de seu tratamento ao longo de todo o século XIX, o que causava grande polêmica sobre a obrigatoriedade, ou não, de recolher os indigentes acometidos pela doença e que vagavam pela cidade. Era preciso recolher os "infelizes lázaros", retirando-os do convívio com a sociedade, todavia, segundo o presidente-provedor Jose Manoel de Freitas, colocá-los nos espaços destinados ao tratamento de doenças curáveis gerava grande desconforto para os internados.

\footnotetext{
Não tem o hospital de caridade accomodações próprias para enfermos desta ordem, e só pelo desejo de prestar algum serviço a esses infelizes, muitos dos quaes vagavam pelas ruas desta cidade, sem abrigo, nem meios de subsistencia, é que tem levado a Santa Casa a recebel-os, acquiescendo assim ás instancias do Exm. Sr. Dr. chefe de policia.

Não posso, porem, concordar que se façam essas células dentro do próprio edifício, onde se encontram constantemente doentes graves, para os quaes o repouso e tranqüilidade são as mais das vezes os únicos favores que se lhes pode prestar, para
}

\footnotetext{
${ }^{31}$ APEM. Fala com que o Exm. Sr. Dr. Cincinnato Pinto da Silva, presidente da província, instalou a 2.a sessão ordinária da 23. a legislatura provincial do Maranhão em 19 de fevereiro de 1881. Maranhão, 1881.
} 
Outros Tempos, vol. 17, n. 30, 2020, p. 134 - 155. ISSN: 1808-8031

que levem, ao menos, para a eternidade, uma idéia, uma lembrança si quer de reconhecimento ${ }^{32}$.

Quando os espaços faltavam e as condições de precariedade se acirravam, o Hospital Militar desempenhava um papel essencial na complementação dos serviços que não eram realizados pelo Hospital de Caridade da Misericórdia. Nos momentos aguçados de epidemias, cabia ao espaço destinado aos militares auxiliar no tratamento dos escravos e desvalidos para que, assim, houvesse mais espaço para o cuidado dos pensionistas no Hospital de Caridade. Por ser um local mais amplo, com capacidade para cerca de 150 leitos em períodos epidêmicos, o Hospital Militar foi utilizado largamente no auxílio aos mais necessitados.

\begin{abstract}
Sendo ainda insufficiente essa casa para a accomodação das pessôas atacadas pela peste, que cada vez se tornava mais intensa, lancei mão do hospital militar, cujos vastos salões admittem para mais de 150 leitos, e se acha nas melhores condições hygienicas, e para esse edifício mandei transportar todos os variolosos das outras enfermarias passando para a Santa Casa da Misericordia a enfermaria das praças e aprendizes marinheiros, accometidos de outras moléstias ${ }^{33}$.
\end{abstract}

As críticas à estrutura deficiente e ao pouco cuidado com a limpeza dos espaços destinados aos doentes eram recorrentes. Em 22 de maio de 1884, numa visita feita pelo presidente da província, Ovídio João Paulo de Andrade, ao Hospital de Caridade a impressão não foi das melhores:

O Im.Morodomo dos hospitaes communicou a mesa que S.Ex Presidente da província, tendo visitado os hospitaes da santa casa da misericórdia viera descontente pelo estado pouco (limpesco) em que os encontrou, estado que elle, Im. Mordomo, disse não poder ou melhor em virtude de pouco pessoal que alli há, e necessitando de reforma a qual elle não havia feito, por não achar para isso disposição da mesa ${ }^{34}$.

Em 1884, segundo o presidente-provedor, Ovídio João Paulo de Andrade, a higiene, elemento central das teorias médicas no século XIX, já não era mais cumprida nos seus elementos básicos, gerando ainda maior discussão sobre a capacidade do Hospital de Caridade em desempenhar suas funções de cura frente à população local.

\footnotetext{
${ }^{32}$ APEM. Fala que o exm. snr. dr. José Manoel de Freitas, presidente da província, dirigiu à assembleia Legislativa Provincial do Maranhão, por ocasião da instalação de sua 1.a sessão da 24.a legislatura no dia 13 de março de 1882; seguida do relatório com que ao mesmo exm. snr. passou a administração da província, o $1^{o}$ vice-presidente, conselheiro João Paulo Monteiro de Andrade, em 7 do referido mez. [n.p.] Typ. do Paiz, 1882.

33 APEM. Fala que o exm. sr. dr. José Manoel de Freitas, presidente da província, dirigiu à assembleia Provincial por ocasião da instalação de sua 2.a sessão da 24.a legislatura, no dia 20 de maio de 1883. Maranhão, Empreza do Paiz, 1883.

${ }^{34}$ APEM. Livros de atas das sessões da Irmandade da Santa Casa da Misericórdia do Maranhão - 1881-1889; 1889-1894.
} 
Outros Tempos, vol. 17, n. 30, 2020, p. 134 - 155. ISSN: 1808-8031

Com relação á Santa Casa da Misericordia devo declarar que o estudo pouco lisongeiro das finanças dessa pia instituição tem motivado as phazes pouco satisfactorias por que tem passado os hospitaes de caridade.

Visitando-os será facil convencer-se V. Exc., de que a caridade não pode ser praticada como fora para desejar-se em estabelecimento dessa ordem.

As regras e preceitos da hygiene não são ali observadas.

O leito que recebe o enfermo sustentado pela caridade nem sempre é preparado de accordo com os princípios salutares da hygiene ${ }^{35}$.

Entrementes, a crise já batia à porta da Misericórdia desde meados do século XIX.

Fruto de prováveis procedimentos escusos dos seus administradores, da falta de recursos públicos e de legados cada vez mais escassos, o Hospital de Caridade ia padecendo cada vez mais com a incapacidade de suprir a demanda por assistência médica em São Luís:

O seu mordomo no hospital, Dr. Sardinha trouxe ao conhecimento da mesa que como doentes de caridade apresentaram-se solicitando leitos muitos indivíduos que a única doença que accusaram era completa decrepitude; que nesses casos sempre ouvia os facultativos do estabelecimento, as quaes julgarão taes indivíduos na convicção de serem admitidos por que é moléstia grave o estar decrépito pelo abatimento geral do organismo. E foi consultar se deveria ou não continuar a attender esses doentes depois de conveniente discussão sobre semelhante consulta foi resolvido do que o mordomo continuasse a dar engresso nas enfermarias como doentes de caridade aquelles indivíduos nas condições apontadas ${ }^{36}$.

As deficiências estruturais iam se avolumando na segunda metade do século XIX. As diversas reformas feitas no edifício do Hospital de Caridade não davam conta da demanda dos pacientes ali tratados. Do primeiro espaço construído, no início do século XIX, pouco restava e os reparos iam sendo cada vez mais urgentes:

\begin{abstract}
Não satisfazendo, porem, segundo estou informado, este edifício á todas as condições exigidas para o fim, não só por serem acanhadas e escuras as divisões internas destinadas para as respectivas enfermarias, como tambem por estar quase todo o madeiramento do tecto arruinado, ameaçando desabar, for elle reconstruído quase todo em 1874, durante a administração do illustrado maranhense, Dr. Augusto Olympio Gomes de Castro.

É mui sensível que, por falta de recursos, não podesse ainda a Santa Casa concluir tão importante edifício, que necessita, alem de uma capella para a celebração dos actos religiosos, de alguns commodos que importam ao bem dos enfermos e do serviço do hospital, como sejam um jardim no grande pateo interno do edifício, a construção de latrinas do melhor systema, casa para banhos e lavagem de roupas, deposito de cadáveres, etc..etc. ${ }^{37}$.
\end{abstract}

\footnotetext{
${ }^{35}$ APEM. Fala que o exm. snr. Ovidio João Paulo de Andrade, dirigiu a assembleia Legislativa Provincial do Maranhão na la sessão da 25a legislatura. Maranhão, Typ. a Vapor da Pacotilha, 1884.

${ }^{36}$ APEM. Livros de atas das sessões da Irmandade da Santa Casa da Misericórdia do Maranhão - 1881-1889; 1889-1894.

${ }^{37}$ APEM. Fala com que o exm. sr. conselheiro João Capistrano Bandeira de Mello abriu a 1.a sessão da 26.a legislatura da assembleia Legislativa Provincial do Maranhão, em 13 de março de 1886. Maranhão, Typ. do Paiz [n.d.]
} 
Outros Tempos, vol. 17, n. 30, 2020, p. 134 - 155. ISSN: 1808-8031

Algumas circunstâncias especiais ajudavam no processo de endividamento da Misericórdia. Em 1886 uma grande seca assolou o Ceará, gerando uma grande onda de imigração para terras maranhenses, muitos chegaram a São Luís bastante debilitados e precisando de atendimento médico no Hospital de Caridade. Tal acontecimento aguçou ainda mais uma crise que se arrastava desde meados do século XIX, aumentando as reclamações da impossibilidade da Santa Casa em atender a demanda dos que ali buscavam tratamento, conforme relato do presidente-provedor Capistrano Bandeira de Melo:

\begin{abstract}
Ainda por ocasião da grande seca que assolou ultimamente a província do Ceará, a Santa Casa da Misericordia prestou importantes serviços, abrindo dous hospitaes nesta cidade para coadjuvar o governo no tratamento dos emigrantes que chegavam a esta província em estado deplorável de abatimento moral e de enfermidades diversas, mediante a quantia de mil reis diários por cada um, o que longe de lhe deixar lucros, ao contrario sobrecarregou-a de despesas extraordinárias, o que foi parte para augmentar o deficit, com que há luctado este estabelecimento ${ }^{38}$.
\end{abstract}

Com a precariedade do Hospital da Misericórdia, é possível que alguns indivíduos de maiores posses tenham optado, a partir de 1862, por procurar tratamento no Hospital Português. Esse novo hospital foi instalado em São Luís, no dia $1^{\circ}$ de dezembro de 1862 , e tinha como objetivo primordial socorrer os portugueses aqui residentes, tratando-os quando doentes. No momento de sua edificação havia, em São Luís, muitas vítimas de febres paludosas adquiridas nos trabalhos de um canal que estava sendo construído, onde tinha sido empregado grande número de colonos portugueses que haviam sido importados para esse fim, e em condições precárias de sobrevivência.

Ao contrário do Hospital de Caridade, administrado pela Misericórdia e que tinha como público alvo também os escravos e desvalidos, o Hospital Português tratou prioritariamente dos portugueses abastados em São Luís, mas reservou alguns leitos para o tratamento dos mais pobres. Prova disso, é que alguns médicos realizaram tratamento gratuito no Hospital Português e utilizaram o espaço para o exercício da prática médica para os profissionais de medicina que aqui residiam: "Com grande dedicação prestou por alguns anos o Dr. José Maria Faria de Matos a sua Casa de Saúde para nela serem tratados os doentes da Sociedade, por preços muito reduzidos uns, e de graça outros". (BPBL. Jornal O Dia de 13 de dezembro de 1863)

\footnotetext{
38 Ibid.
} 
Outros Tempos, vol. 17, n. 30, 2020, p. 134 - 155. ISSN: 1808-8031

Este hospital passou a ter grande destaque na composição imobiliária da capital, sendo um dos lugares mais visitados e concorridos da parte central de São Luís à época, e o primeiro estabelecimento a receber energia elétrica no século XIX. A única estatística que encontramos do Hospital trazia os seguintes dados:

Desde que se abriu o nosso Hospital, isto é, desde 16 de dezembro de 1867 até hoje, tem entrado para as suas enfermarias 215 enfermos de todas as classes, sendo: pensionistas $1^{\mathrm{a}}$ classe, 47; pensionistas de $2^{\mathrm{a}}$ classe, 46; sócios desvalidos, 49; desvalidos não sócios, 73 = 215./ Foram curados 179; morreram 24; em tratamento $12=215$

842 sócios das seguintes classes: Contribuintes 656; beneméritos, 38; remidos, 33; dispensados de pagamento, 4 ; ausentes no interior e no exterior, $111^{39}$.

Em relação ao trabalho desenvolvido pelos médicos em São Luís, o serviço gratuito praticado por esses profissionais nos hospitais administrados pela Santa Casa foi, muitas vezes, uma forma encontrada pelas mesas da Misericórdia para economizar com os profissionais que desempenhavam suas funções no Hospital de Caridade, além de proporcionar um espaço para que médicos recém-chegados, e em busca de se fazerem conhecidos, pudessem utilizar o recinto dos hospitais para ali tornar públicas suas habilidades, além de aprimorar técnicas aprendidas nos seus locais de formação. Todavia, a prestação de serviços gratuitos por médicos gerava também os seus inconvenientes:

\begin{abstract}
O mordomo do hospital de caridade, dr. Manoel da silva sardinha, fez ver a mesa a conveniência de restabelecer os ordenados dos médicos e cirurgião que servem no mesmo hospital, porque não só a administração poderia ser mais eficazmente, visto não podendo elles allegar a circunstancia de prestarem seus serviços gratuitos, quando se torne urgente e extraordinário o seu comparecimento ali, por casos também estraordinarios e urgentes das clinicas medica e cirúrgica, como também ser um acto de justiça a remuneração de semelhantes serviços; e assim propunham para cada um desses facultativos o ordenados de 50.000.00, que outro'ra recebiam mensalmente, sendo que no orçamento do corrente anno, apresentado nesta secção a verba precisa a ultima proposta, foi approvada ficando desde logo, reestabelecido o ordinário de 50.000 mensais para cada um dos médicos encarregados daquellas clinicas, e assim com direito a serem pagos do mês corrente em diante ${ }^{40}$.
\end{abstract}

O não recebimento de ordenados mensais por parte dos médicos que prestavam serviços para o Hospital de Caridade gerava também a falta de compromisso para com as funções a serem desempenhadas dentro do estabelecimento. Como forma de cobrar a presença desses profissionais, principalmente em momentos de urgência, resolveu-se restabelecer os

\footnotetext{
${ }^{39}$ BIBLIOTECA PÚBLICA BENEDITO LEITE. Jornal A Pacotilha, de 12 de dezembro de 1890.

${ }^{40}$ APEM. Livros de atas das sessões da Irmandade da Santa Casa da Misericórdia do Maranhão - 1881-1889; 1889-1894.
} 
Outros Tempos, vol. 17, n. 30, 2020, p. 134 - 155. ISSN: 1808-8031

seus pagamentos para que, assim, eles pudessem estar à disposição dos pacientes internados, que necessitavam ser avaliados com regularidade. Nos momentos em que os médicos realizavam serviços gratuitos no Hospital, eram recorrentes as reclamações acerca de atrasos, faltas, que acarretavam em grandes prejuízos para o cotidiano de cura dos pacientes.

\begin{abstract}
Como substituto do Mordomo do hospital declarou mais Monsenhor Mourão, que não há regularidade nas visitas medicas no dito hospital que ellas devem ser feitas logo de manhã, mas as vezes fazem-se em horas incertas, ás 11 horas e ao meio dia, inconveniente para o serviço do hospital, e ás vezes não vai o medico. Acha que isto é muito irregular n'um estabelecimento desta ordem, quando não pudesse vir o medico devia ao menos mandar um seu collega, porque há sempre que fazer e providenciar. Que não pode haver hospital sem visitas medicas, que o art. 31 do seu Regulamento diz que os facultativos visitarão diariamente as enfermarias a seu cargo. Que convinha, pois, tomar uma providencia a semelhante respeito e requeria uma sessão breve para esse fim, presente o mordomo effectivo Marques Rodrigues. O que foi acceito. ${ }^{41}$
\end{abstract}

Certo é que as tentativas de conter a crise não foram suficientes para retirar o caráter oneroso do Hospital de Caridade e dirimir as diversas conjunturas de epidemias. Falta de leitos e de profissionais, bem como a concorrência de outras práticas de cura propiciaram longas discussões sobre a credibilidade da Santa Casa no que se refere ao auxílio médico oferecido aos que dela dependiam. Tais deficiências ajudaram decisivamente na perpetuação de problemas que foram se avolumando com maior ou menor intensidade, de acordo com momentos de maior bonança ou escassez. Os momentos epidêmicos são oportunos para visualizarmos as estratégias utilizadas para suprir carências estruturais em momentos de profunda tensão.

\footnotetext{
${ }^{41}$ APEM. Atas das Sessões da Santa Casa da Misericórdia, 1886, p. 50.
} 